\title{
The effect of Psoroptes ovis infestation on ovine epidermal barrier function
}

\author{
Miriam R Stoeckli², Tom N McNeilly ${ }^{1}$, David Frew ${ }^{1}$, Edward J Marr ${ }^{1}$, Alasdair J Nisbet ${ }^{1}$, \\ Adri HM van den Broek ${ }^{2,3}$ and Stewart TG Burgess ${ }^{1 *}$
}

\begin{abstract}
Sheep scab is an intensively pruritic, exudative and allergic dermatitis of sheep caused by the ectoparasitic mite Psoroptes ovis. The purpose of the present study was to investigate the effect of $P$. ovis infestation on different components of the ovine epidermal barrier within the first 24 hours post-infestation (hpi). To achieve this, the expression of epidermal differentiation complex (EDC) genes and epidermal barrier proteins, the nature and severity of epidermal pathology and transepidermal water loss (TEWL) were evaluated.

By 1 hpi a significant dermal polymorphonuclear infiltrate and a significant increase in TEWL with maximal mean TEWL (598.67 g/ $\left.\mathrm{m}^{2} \mathrm{~h}\right)$ were observed. Epidermal pathology involving intra-epidermal pustulation, loss of epidermal architecture and damage to the basement membrane was seen by 3 hpi. Filaggrin and loricrin protein levels in the stratum corneum declined significantly in the first $24 \mathrm{hpi}$ and $\mathrm{QPCR}$ validation confirmed the decrease in expression of the key EDC genes involucrin, filaggrin and loricrin observed by microarray analysis, with 5.8-fold, 4.5-fold and 80 -fold decreases, respectively by $24 \mathrm{hpi}$.

The present study has demonstrated that early $P$. ovis infestation disrupts the ovine epidermal barrier causing significant alterations in the expression of critical barrier components, epidermal pathology, and TEWL. Many of these features have also been documented in human and canine atopic dermatitis suggesting that sheep scab may provide a model for the elucidation of events occurring in the early phases of atopic sensitisation.
\end{abstract}

\section{Introduction}

Sheep scab is an intensely pruritic, exudative, allergic dermatitis caused by the ectoparasitic mite Psoroptes ovis. It is a highly contagious disease and of major economic and welfare importance to the UK sheep industry [1-4]. The surface-living mite deposits excretory and secretory products containing homologues of known house dust mite (HDM) allergens and enzymes onto the stratum corneum $[5,6]$. Clinical observation and histological studies have shown that by 24 hours post-infestation (hpi) of naïve sheep these allergens and enzymes have penetrated the stratum corneum and initiated an intense immunoinflammatory response [7] that culminates in immediate IgE-mediated $[8,9]$ and delayed, cell-mediated, hypersensitivity reactions [9]. This early, intense inflammatory response appears to be critical in determining the direction of the subsequent

\footnotetext{
* Correspondence: stewart.burgess@moredun.ac.uk

${ }^{1}$ Moredun Research Institute, Pentlands Science Park, Bush Loan, Edinburgh, Midlothian, Scotland EH26 OPZ, United Kingdom

Full list of author information is available at the end of the article
}

acquired immune response and is dependent on the rapid penetration of mite products through the epidermal barrier.

Integrity of the skin barrier is critical in preventing excessive transepidermal water loss (TEWL) and in skin defence by reducing penetration of exogenous molecules including allergens [10]. The stratum corneum plays a pivotal role in skin barrier function and is composed of anucleated corneocytes, embedded in an extracellular lipid matrix [11] and encased by a cornified envelope consisting of crosslinking proteins such as filaggrin, loricrin and involucrin and free amino acids, a combination forming what has been termed natural moisturising factor (NMF) [12,13]. Among the allergens and enzymes deposited on the stratum corneum by $P$. ovis are Pso o 1 and Pso o 3 which are, respectively, homologues of the proteolytic enzymes $\operatorname{Der} p 1$ (cysteine protease) and $\operatorname{Der} p 3$ (serine protease) produced by the HDM Dermatophagoides pteronyssinus and Sar s 3 (serine protease) produced by the scabies mite Sarcoptes scabiei [14]. By analogy, proteolytic activity of these enzymes may disrupt the epidermal barrier by
C Biomed Central

(C) 2013 Stoeckli et al.; licensee BioMed Central Ltd. This is an Open Access article distributed under the terms of the Creative Commons Attribution License (http://creativecommons.org/licenses/by/2.0), which permits unrestricted use, distribution, and reproduction in any medium, provided the original work is properly cited. 
cleavage of tight junctions [15,16] and digestion of filaggrin [14] increasing barrier permeability and TEWL, leading to the initiation of a skin drying cycle and enabling the ingress of exogenous allergens [17].

In addition, recent transcriptome microarray analysis of the ovine cutaneous response up to 24 hpi with $P$. ovis demonstrated significant alterations in the expression of genes located in the epidermal differentiation complex (EDC) including significant down regulation of filaggrin, loricrin and involucrin [18]. Earlier microarray analyses revealed similar alterations in the expression of EDC genes in human atopic dermatitis, and notably the repressed expression of filaggrin, loricrin and involucrin $[19,20]$. The importance of these proteins in barrier function is indicated by the observation that loss of function mutations in filaggrin, the most intensively studied EDC gene, are associated with diseases with compromised epithelial barrier function such as atopic dermatitis, ichthyosis, psoriasis and asthma [21]. Skin barrier function has been traditionally assessed by measurement of TEWL $[22,23]$ which is increased in non-lesional and lesional skin of atopic humans [24,25] and dogs [26] compared to healthy individuals.

It is clear that P. ovis-derived enzymes and allergens are able to penetrate the skin barrier initiating a dynamic, multi-faceted immunoinflammatory response involving alterations in the expression of a wide range of genes and proteins including those of the EDC [18]. As early events appear to be of critical importance in the establishment of a sheep scab infestation, the purpose of the present study was to focus on the first $24 \mathrm{hpi}$, investigating the effect of mite products on different components of the ovine epidermal barrier - a study not reported previously. Here we demonstrate early and significant changes in the expression of selected EDC genes following exposure of sheep skin to $P$. ovis. We employed immunohistochemistry to evaluate the expression of filaggrin and loricrin at the protein level in the stratum corneum and document the nature and severity of histological changes in the skin following infestation. Finally we assessed the influence of these mite-induced changes on skin barrier function through the measurement of TEWL. An understanding of these initial events may provide new insights into the pathogenesis of sheep scab and of other allergic diseases such as atopic dermatitis that compromise epidermal barrier function and integrity.

\section{Materials and methods}

\section{Animal study, P. ovis infestation and skin biopsy} collection and fixation

Ethical approval for this study was obtained from the Moredun Research Institute (MRI) Experiments Committee and animals were monitored daily in accordance with guidelines agreed with the UK Home Office. P. ovis mites (mixed population consisting of adults, nymphs and larvae) were harvested from infested donor animals maintained at MRI. Sheep scab naïve, $\sim 9$ month old Scotch mule lambs $(n=9)$ were maintained at MRI. Immediately prior to infestation with $P$. ovis, an area of the left flank (50 cm (long) $\times 20 \mathrm{~cm}$ (deep)) of each animal was shaved to the skin with electric clippers and two plastic isolation chambers $(1 \mathrm{~cm}$ deep $\times 1 \mathrm{~cm}$ diameter $)$ were adhered to the skin with surgical glue (Indermil, Henkel, Dusseldorf, Germany). After one hour to allow glue drying and chamber adhesion and following the administration of a local anaesthetic $(1 \mathrm{~mL}, 2 \%(\mathrm{w} / \mathrm{v})$ lignocaine hydrochloride and 0.001\% (w/v) adrenaline (Lignol, Arnolds, Harlescott, UK)) two skin biopsies were removed from each animal, one from within each isolation chamber, using a disposable $8 \mathrm{~mm}$ biopsy punch (Henry Schein Animal Health, Dumfries, UK), these samples represented time 0 (uninfested). Following biopsy removal the sample site was sealed with Michel surgical suture clips (Henry Schein Animal Health, UK). The skin biopsies were cut into two and one half was fixed in $5 \mathrm{~mL}$, $4 \%$ paraformaldehyde in phosphate buffered saline (PBS, pH7.4) for $6 \mathrm{~h}$ then transferred and stored in $70 \%$ ethanol prior to processing. The other half of each biopsy was placed into $5 \mathrm{~mL}$ RNALater solution (Life Technologies Corporation, Paisley, UK) and stored at $4^{\circ} \mathrm{C}$ overnight prior to storage at $-20^{\circ} \mathrm{C}$ and subsequent RNA extraction. For the time course samples, eight further isolation chambers were adhered to the shaven area of the left flank of each animal as described above. Approximately 20-50 mites were placed directly onto the skin within each chamber and then after carefully removing mites with a cotton bud, biopsies were taken from within two chambers per time point, as detailed above, at the following intervals 1, 3, 6 and 24 hpi. After collection biopsies were cut into two halves and fixed and stored as described above.

\section{Extraction of RNA from ovine skin biopsies}

RNA extraction from thawed skin biopsy samples was performed as described previously [18]. RNA sample quality was assessed on an Agilent Bioanalyser (Agilent Technologies UK, Wokingham, UK) an RNA Integrity Number (RIN) was obtained for each sample and RNA yield was assessed on a ND-1000 Nanodrop spectrophotometer (Thermo Scientific Ltd, Cramlington, UK). RNA samples with a RIN $>7.5$ were considered to be of acceptable quality for downstream analysis [27]. Duplicate RNA samples from each time point, per animal were then pooled (5 $\mu \mathrm{g}$ RNA from each of 2 replicates for time $=0$ and $1,3,6$ and $24 \mathrm{hpi}$ samples, forming $10 \mu \mathrm{g}$ total RNA pools per time point/animal). 


\section{Microarray analysis of ovine skin biopsy samples following infestation with $P$. ovis}

The experimental details of the microarray study for the analysis of the host response to skin infestation with $P$. ovis mites over a $24 \mathrm{~h}$ time course have been described previously [18]. Briefly, this analysis identified 1552 genes significantly differentially expressed (fold-change greater than 1.8 and a false discovery corrected $p$-value $<0.05)$ at the transcript level over the time course of $P$. ovis infestation [18]. Two clusters of genes implicated in the control of terminal differentiation of keratinocytes were identified and their up- and down-regulation at 24 hpi compared to baseline $(0 \mathrm{~h})$ was assessed.

\section{Quantitative real time PCR (qPCR) validation of selected EDC gene expression}

qPCR was used to verify the differential expression of three EDC genes; filaggrin (FLG), loricrin (LOR) and involucrin (IVL) using RNA extracted from the ovine skin biopsies obtained from 6 individual sheep across the $24 \mathrm{~h}$ time course of infestation with samples taken at 0 (baseline), 1, 3, 6 and 24 hpi. External primer sets for FLG and IVL were designed on the bovine gene sequences and used to amplify gene fragments for qPCR standard curve generation, the sequences were as follows: Ext-FLG-Forward: 5'GAAAGAGGGAAAAA GAGACATGG'3; Ext-FLG-Reverse: 5'CCTTCGCTATC GCTGGCCTG'3; Ext-IVL-Forward: 5'ATACCCAGCA GGAGCAAGTG'3; Ext-IVL-Reverse: 5'CTTCTCCTGT TCCAGCTGTCC '3. Internal primer sets for FLG and $I V L$ were also designed on the bovine gene sequences and were as follows: Int-FLG-Forward: 5'TGGAAGAC CTGGTTCAGCTT’3; Int-FLG-Reverse: 5'TGCTTCCA GATCCAGAGGAG'3; Int-IVL-Forward: $5^{\prime}$ GCCTCAG AAAGCAGAACACC'3; Int- $I V L$-Reverse: 5 'GACTGG GTGGATCTCTTGGA'3.

Total RNA was used as template for the generation of complementary DNA (cDNA) using Superscript II (Life Technologies Corporation, UK) and anchored oligo (dT) primers (Sigma, UK) according to the manufacturer's protocols. For the validation of FLG and IVL a two-step qRT-PCR was performed using SYBR green absolute quantification and the standard curve method. Plasmids and standard curves for the selected genes and the endogenous control glyceraldehyde 3-phosphate dehydrogenase $(G A P D H)$ were prepared as previously described $[28,29]$. Serial 1:10 dilutions of plasmid containing the gene of interest ranging from $10^{2}$ to $10^{8}$ copies per $\mu \mathrm{L}$ were run in parallel with each series of samples on an ABI Prism 7000 Sequence Detection System (Life Technologies Corporation, UK) allowing automatic standard curve generation. PCR efficiencies calculated from the slopes were consistently $\geq 95 \%$. The number of copies per $\mu \mathrm{L}$ of sample was calculated and results normalized to the GAPDH endogenous control, the expression of which had been shown not to vary significantly with infestation based on the microarray data from the same study [18]. Samples and standards were run in triplicate and melting curve analysis was performed at the end of each PCR to verify product specificity. Validation of LOR expression was performed using the Taqman relative quantification, 2-ddCt method $[30,31]$. As no ovine $L O R$ sequence was available at the time of study a pre-validated "assay-on-demand" specific primer and probe set based on bovine $L O R$ was used for analysis of skin biopsy RNA (Life Technologies Corporation, UK). cDNA was assayed for $L O R$ expression using pre-validated Taqman primers and probeset (Assay ID: Bt03269087_m1, Life Technologies Corporation, UK) and performed in quadruplicate. $L O R$ expression results were normalised to GAPDH using a Taqman pre-validated "assay-on-demand" primer and probeset based on bovine GAPDH and previously shown within our lab to cross react with the ovine gene (Assay ID: Bt03210913_g1, Life Technologies Corporation, UK). Gene expression differences across the $24 \mathrm{~h}$ time course of infestation were calculated by relative quantification using time 0 (uninfested skin biopsy RNA samples) as the control compared to the 1, 3, 6 and 24 hpi samples.

\section{Immunohistochemical labelling and measurement of intensity of fluorescent labelling for filaggrin and loricrin protein in ovine skin sections}

Immunohistochemistry was performed on serial $5 \mu \mathrm{m}$ tissue sections of paraformaldehyde fixed samples. Sections were deparaffinized in xylene and rehydrated in water. Antigen retrieval was performed on sections to be labelled for filaggrin by autoclaving in $10 \mathrm{mM}$ citrate buffer of $\mathrm{pH} 6$ at $121^{\circ} \mathrm{C}$ for $10 \mathrm{~min}$. Subsequently, these sections and those to be labelled for loricrin were rinsed twice in PBS (pH7.4) and washed in $0.5 \%$ Tween 80 in PBS (PBST80) for $5 \mathrm{~min}$. Endogenous peroxidase activity was quenched by incubation in $0.3 \% \mathrm{H}_{2} \mathrm{O}_{2}$ in PBST80 for $20 \mathrm{~min}$ and followed by a $5 \mathrm{~min}$ wash in PBST80 before loading into a Sequenza slide rack (Thermo Scientific Ltd, UK). Following a further PBS wash, sections were incubated in $25 \%$ normal goat serum (NGS) to block non-specific tissue antigens. Sections were then incubated overnight at $4^{\circ} \mathrm{C}$ with either, $100 \mu \mathrm{L}$ mouse monoclonal anti-filaggrin antibody (SPM181, Abcam, Cambridge, UK) at 1:25 in 10\% NGS/PBST80 or with $100 \mu \mathrm{L}$ of rabbit polyclonal anti-loricrin antibody (AB85679, Abcam UK) at 1:2000 $(0.5 \mu \mathrm{g} / \mathrm{mL})$ in $10 \%$ NGS/PBST80. Overnight incubation of appropriate isotype controls was carried-out in 10\% NGS/PBST80 (1:25 dilution mouse isotype control mAb VMP21 or $0.5 \mu \mathrm{g} / \mathrm{mL}$ purified rabbit immunoglobulin (Sigma Aldrich Company Ltd, Gillingham, UK)) for mouse anti-filaggrin and rabbit anti-loricrin primary antibodies respectively. In 
addition to isotype-controls, controls without antibodies were performed by incubation with $100 \mu \mathrm{L}$ $10 \%$ NGS/PST80. Sections were rinsed twice in PBS prior to incubation with $100 \mu \mathrm{L}$ of Alexa-fluor 488 goat anti-mouse IgG (1:1000, Life Technologies Corporation, UK) or Alexa-fluor 488 goat anti-rabbit IgG (1:1000, Life Technologies Corporation, UK) in 10\% NGS/PBST80 for $1 \mathrm{~h}$ in the dark. Slides were mounted in Mowiol $^{\circledR}$ 4-88 (Merck KGaA, Darmstadt, Germany) and stored at $4^{\circ} \mathrm{C}$ prior to visualisation.

At each time-point (0, 1, 3, and 24 hpi) five random fields of epidermis and superficial dermis were captured at 40× magnification using an AxioCam MRm digital camera mounted on a Axiovert $200 \mathrm{M}$ inverted fluorescence microscope equipped with an ApoTome slider module (Carl Zeiss Ltd, Welwyn Garden City, UK). Images were processed using AxioVision version 4.7.2 digital image processing software (Carl Zeiss Ltd, UK). An identical exposure time was used across all fields/time points. In pictures with patchy fluorescence or loss of fluorescence, composite images were taken using both fluorescence and phase contrast microscopy to identify the epidermis. The mean fluorescence intensity (MFI)/mm epidermis for both filaggrin and loricrin labelling was determined for each tissue section using ImageJ, version 1.42 software [32], with five fields evaluated per section.

\section{Qualitative and semi-quantitative histopathological analysis}

Histopathological analysis was performed on $5 \mu \mathrm{m}$ sections of paraformaldehyde fixed tissue from all 9 sheep at the following time points $(0 \mathrm{~h}, 1 \mathrm{hpi}, 3 \mathrm{hpi}$ and $24 \mathrm{hpi}$ ). Sections were stained with haematoxylin and eosin and were mounted in Histomount ${ }^{\circledR}$ (Life Technologies Corporation, UK).

\section{Assessment of epidermal changes}

On the basis of earlier studies [8,9] a blinded evaluation of the hematoxylin and eosin (H\&E) stained sections was undertaken. Three criteria for the histopathological assessment of epidermal change (subcorneal and parafollicular pustulation, disruption of normal structure, loss of basement membrane) were identified. The severity of epidermal changes was classified as mild $(<1 / 3$ of the epidermis affected), moderate (1/3-2/3 of the epidermis affected) and severe ( $>2 / 3$ of the epidermis affected).

\section{Assessment of dermal infiltrate}

The predominant cell type present in the dermal infiltrate was assessed subjectively and classified as either mononuclear or polymorphonuclear. The severity of the infiltrate was categorised as mild, moderate or severe. In addition, polymorphonuclear cells were counted in 25 successive images taken by an Olympus DP72 camera attached to an Olympus BX41 microscope at $\times 60$ magnification. Graticules were entered with imaging software (Cell, Olympus Cell Family, Olympus UK Ltd, Southend-on-sea, UK) to simplify cell counting. Intravascular and intrafollicular polymorphonuclear cells were excluded from the count and large vessels and follicles were subtracted from the total area counted.

\section{Determination of transepidermal water loss (TEWL)}

TEWL was evaluated with a closed chamber VapoMeter (Delfin Technologies Ltd, Kuopio, Finland) using the standard instrument adaptor (diameter $=11 \mathrm{~mm}$ ) with readings recorded in $\mathrm{g} / \mathrm{m}^{2} \mathrm{~h}$. For this study four additional sheep were infested with $P$. ovis (20-50 mites) on two adjacent sites on the left flank. Prior to infestation, three measurements of TEWL were taken on a shaven area of the flank of each animal (representing the time 0 or baseline sample). Following infestation a further three measurements of TEWL were taken at the two sites of infestation on each sheep at 1, 3, 6 and 24 hpi. Average values for each animal at each time point were obtained by calculating the mean of the repeated measurements across both infestation sites. In addition, further measurements were taken from uninfested skin adjacent to the infestation sites at each of the four time points to ensure accuracy of measurements.

\section{Statistical analysis}

All statistical analyses were performed using GraphPad Prism software (Version 5, GraphPad Software Inc, La Jolla, USA). qPCR, fluorescent intensity, PMN cell count and TEWL data were found to be normally distributed and data analyses were performed using a repeated measures one-way ANOVA analysis with a Tukey post-hoc test. $P$-values of $<0.05$ were considered significant.

\section{Results}

Microarray analysis of ovine skin following $P$. ovis infestation

Two clusters of EDC genes, implicated in the control of terminal differentiation of keratinocytes, were significantly differentially expressed in ovine skin across the 24 h time course of infestation with $P$. ovis (Figure 1). The first cluster contained EDC genes with increased expression across the time course of infestation with peak expression by $24 \mathrm{hpi}$ and included the small proline rich proteins (SPRRs) SPRR2A (324-fold increase) and $S P R R 2 E$ (average 136-fold increase) and the S100 calcium binding proteins, S100A9 (90-fold increase) and S100A12 (66-fold increase). The second cluster contained EDC genes with decreased expression by 24 hpi and included LOR (26-fold decrease), FLG (5.8fold decrease), S100 calcium binding protein A3 (S100A3, 2-fold decrease) and late cornified envelope $1 \mathrm{~B}$ (LCE1B, 2-fold decrease). 


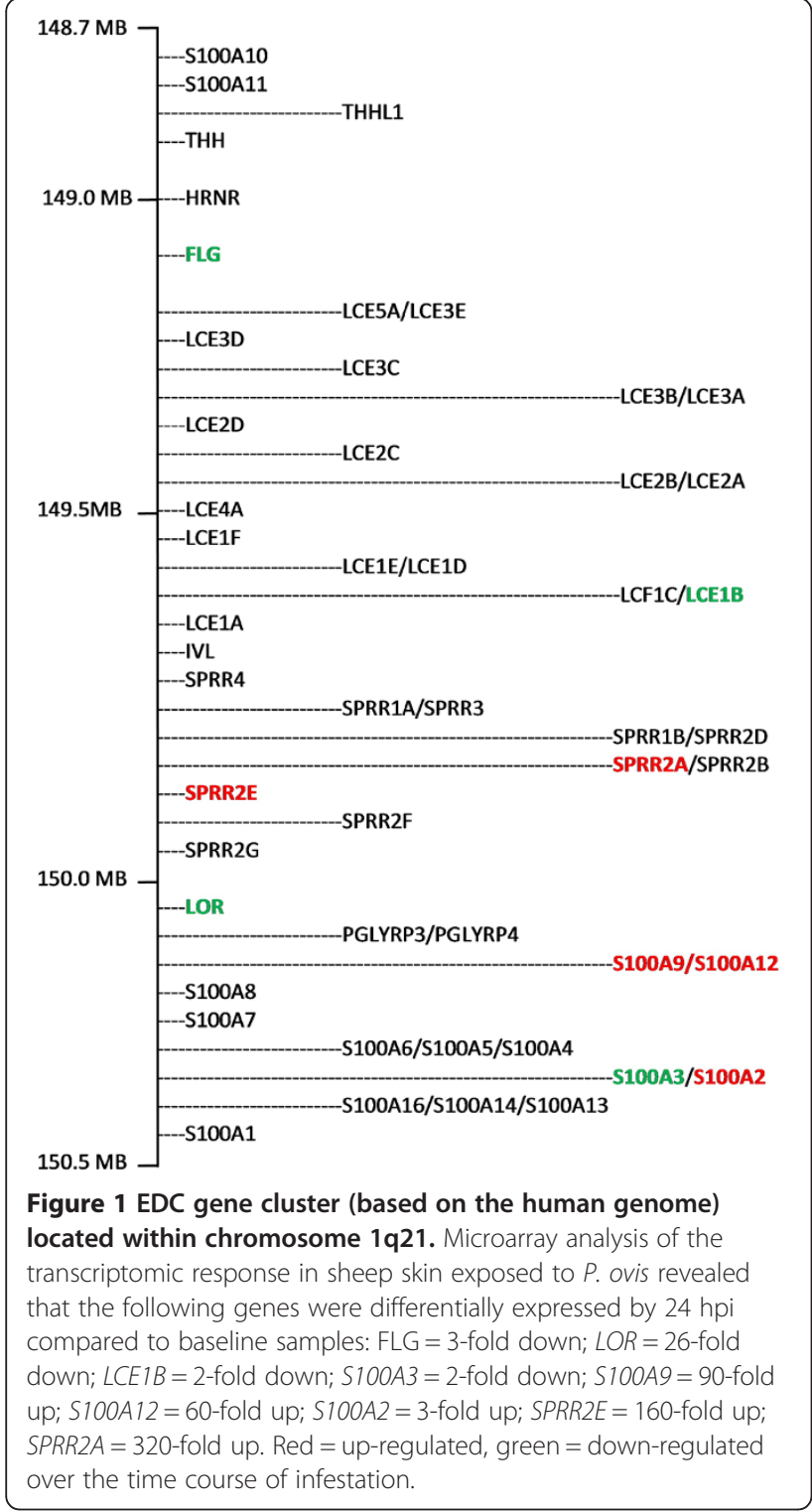

qPCR validation of selected EDC gene expression

IVL (Figure 2a) was significantly differentially expressed by 24 hpi with a 5.8 fold decrease compared to time 0 $(p \leq 0.05)$. FLG (Figure $2 \mathrm{~b}$ ) was also significantly differentially expressed by $3(p \leq 0.05)$ and 24 hpi $(p \leq 0.05)$ with respectively, a 3.48 -fold and 4.46-fold decrease compared to $1 \mathrm{hpi}$. LOR gene expression (Figure 2c) was the most significantly down-regulated of the three EDC genes assessed with an 80-fold reduction in expression at 24 hpi compared to time $0(p \leq 0.001)$.

\section{Immunohistochemical labelling of filaggrin and loricrin protein in ovine skin sections}

Representative images of immunohistochemical labelling of filaggrin and loricrin are shown in Figure 3a, with the $\mathrm{MFI} / \mathrm{mm}$ epidermis for filaggrin and loricrin labelling over the time-course of infection shown in Figures $3 \mathrm{~b}$ and $\mathrm{c}$, respectively. One of the nine sheep used had to be excluded as significant background staining affected the measurements. The ranges and averages of the mean fluorescence intensity $/ \mathrm{mm}(\mathrm{MFI} / \mathrm{mm})$ of the remaining eight sheep for filaggrin and loricrin at $0 \mathrm{~h}, 1 \mathrm{hpi}, 3 \mathrm{hpi}$ and 24 hpi are shown in Table 1 . There were significant differences in filaggrin staining between time 0 and 24 hpi $(p<0.001)$, between 1 and 24 hpi $(p<0.001)$ and between 3 and 24 hpi $(p<0.001)$ (Figure 3b). Fluorescent intensity for loricrin at $24 \mathrm{hpi}$ was significantly lower $(p<0.01)$ than at 1 hpi (Figure 3c).

\section{Quantitative and semi-quantitative histopathological analysis \\ Epidermal changes}

Details of epidermal changes and their severity at $3 \mathrm{hpi}$ and 24 hpi are summarized in Table 2, and representative images of H\&E sections from one animal over the time-course of infection are shown in Figure 3a. Epidermal changes were first observed at $3 \mathrm{hpi}$ with $3 / 9$ biopsies showing mild to moderate pustule formation, $7 / 9$ biopsies showing mild to moderate loss of epidermal architecture and 7/9 biopsies with severe disruption of the basement membrane. By 24 hpi epidermal changes were generally more severe, with 7/9 biopsies exhibiting severe pustule formation or loss of epidermal architecture and $3 / 9$ biopsies exhibiting severe loss of the epidermal basement membrane. No evidence of epidermal hyperplasia was detected at 3 or $24 \mathrm{hpi}$.

\section{Dermal infiltrate of polymorphonuclear cells}

Mean polymorphonuclear (PMN) cell counts per $\mathrm{mm}^{2}$ at time 0 (baseline), 1, 3 and 24 hpi are presented in Table 1 and Figure 3d. All polymorphonuclear cells were counted and comprised predominantly eosinophils. There was a significant increase in polymorphonuclear cells in $\times 60$ microscopic fields between time 0 and 1 hpi $(p<0.001)$, time 0 and 3 hpi $(p<0.001)$ and time 0 and 24 hpi $(p<0.001)$. Furthermore, there was a significant increase between 1 and 3 hpi $(p<0.01)$ and between 1 and 24 hpi $(p<0.01)$.

\section{Trans-epidermal water loss (TEWL)}

Mean TEWL $\left(\mathrm{g} / \mathrm{m}^{2} \mathrm{~h}\right)$ at time 0 (baseline), at 1, 3, 6 and 24 hpi are presented in Table 1 and Figure 4. There were significant changes between time 0 and 1 hpi $(p<0.001)$ time 0 and 3 hpi $(p<0.001)$ time 0 and 6 hpi $(p<0.01)$ and time 0 and 24 hpi $(p<0.01)$. There were also significant differences between 1 and 24 hpi $(p<0.01)$ and 3 and 24 hpi $(p<0.01)$.

\section{Discussion}

In this study we have demonstrated that within $24 \mathrm{~h}$ of infestation, $P$. ovis triggers a significant decrease in 

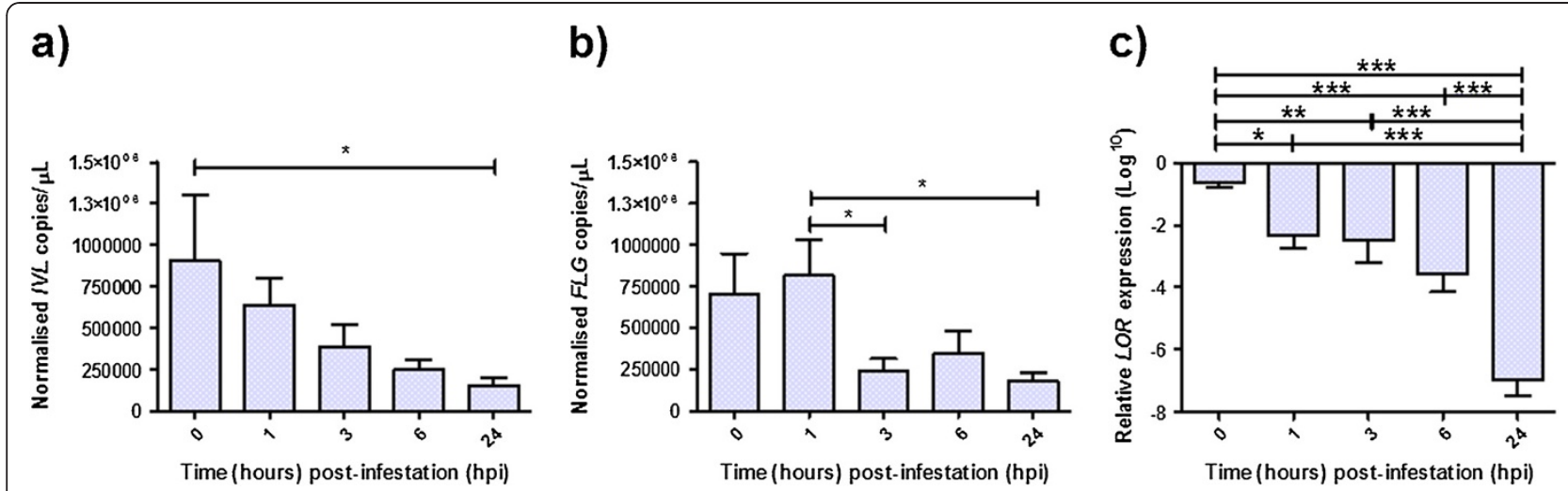

Figure 2 qPCR validation of $I V L, F L G$ and $L O R$ expression in ovine skin following $P$. ovis infestation. Expression data across six individual sheep for IVL (a) FLG (b) and LOR (c). Values for IVL and FLG were normalised to the expression of the ovine housekeeping gene GAPDH and expressed as copies/ $\mu \mathrm{L}$ at each time point across six animals. $L O R$ gene expression was assessed using the relative quantification ddCt method and normalised to the time $=0$ sample. ${ }^{*}=p<0.05,{ }^{* *}=p<0.01,{ }^{* *}=p<0.001$. Error bars show standard error of the mean (SEM).

expression of selected EDC genes and initiates significant breakdown of the epidermal barrier function evidenced by reduced levels of selected EDC proteins at the epidermal surface, cutaneous histopathology and significant TEWL.

As reported earlier, transcriptome microarray analysis of the ovine cutaneous response to $P$. ovis demonstrated that expression of a cluster of EDC genes including those for FLG, LOR and IVL was decreased with maximal repression by 24 hpi [18]. qPCR, employed in the present study, confirmed the decreases in IVL, FLG, and $L O R$ gene expression with 5.8-fold, 4.46-fold and 80-fold decreases, respectively by $24 \mathrm{hpi}$ compared to time 0 (baseline) samples in ovine skin. The canonical Th2 cytokines, IL4 and IL13 have been shown to be over expressed in atopic skin [20,33,34] and are able to trigger down-regulation of FLG [35,36], LOR [20], IVL [20] in human keratinocytes. There is also a growing body of evidence to support a role for the Th2-associated transcription factor STAT6 in this pathway [37]. Therefore, atopic patients may acquire a filaggrin deficiency and the resulting epidermal barrier dysfunction as a result of a Th2-driven inflammatory response. A similar bias towards a Th2 dominated immune response has been demonstrated by transcriptomic analysis of the ovine response to $P$. ovis infestation [18] and suggests that Th2-cytokines may also be involved in suppression of filaggrin synthesis in $P$. ovis infested skin.

In contrast to acquired filaggrin deficiency, reduced FLG expression can also be inherited by loss-of-function mutations in FLG, which have been demonstrated in patients with atopic dermatitis, psoriasis and ichthyosis vulgaris [38] and potentially occur in canine atopy [39]. However, mutations in FLG have not yet been demonstrated in sheep but breed variation in susceptibility to sheep scab has been reported and although only anecdotal may conceivably be related to EDC gene mutations/ polymorphisms [40].

The present study recorded a significant decline in the fluorescent intensity of staining for both filaggrin and loricrin protein in the stratum corneum by 24 hpi demonstrating the involvement of these integral constituents of the cornified envelope in the pathology of sheep scab. This reduction in staining intensity may be attributable to active down-regulation of gene expression, potentially as a consequence of the Th2-dominated immune response as previously discussed, and the consequent reduction in protein synthesis. However, as the decrease in both filaggrin and loricrin gene expression and protein levels mirrored the development of pathological changes within the epidermis, it is also possible that loss of keratinocytes, the principal cellular source of these proteins [12], contributed to the reduced levels of filaggrin and loricrin observed in this study. Nevertheless, it is unlikely that keratinocyte loss is solely responsible as increased expression of the keratinocyte-specific EDC genes, $S P R R 2 A$ and SPRR2E, was observed at $24 \mathrm{hpi}$, suggesting that significant numbers of viable keratinocytes were present even when levels of filaggrin and loricrin were lowest. Another possible mechanism for the reduced levels of filaggrin protein is active cleavage of protein by mite proteases: earlier in vitro studies have shown that a recombinant scabies mite protease, $\operatorname{Sar} s 3$, a homologue of Der $p 3$ and Pso o 3, is capable of cleaving filaggrin and that filaggrin protein can be immunolocalised to the scabies mite digestive tract [14]. Therefore, the rapid reduction in fluorescent intensity observed in the present study may have resulted from a combination of reduced protein synthesis due to active down-regulation of gene expression, loss of keratinocytes as a result of $P$. ovis induced pathology and the action of mite-derived proteolytic enzymes. 
a)

\section{Filaggrin}
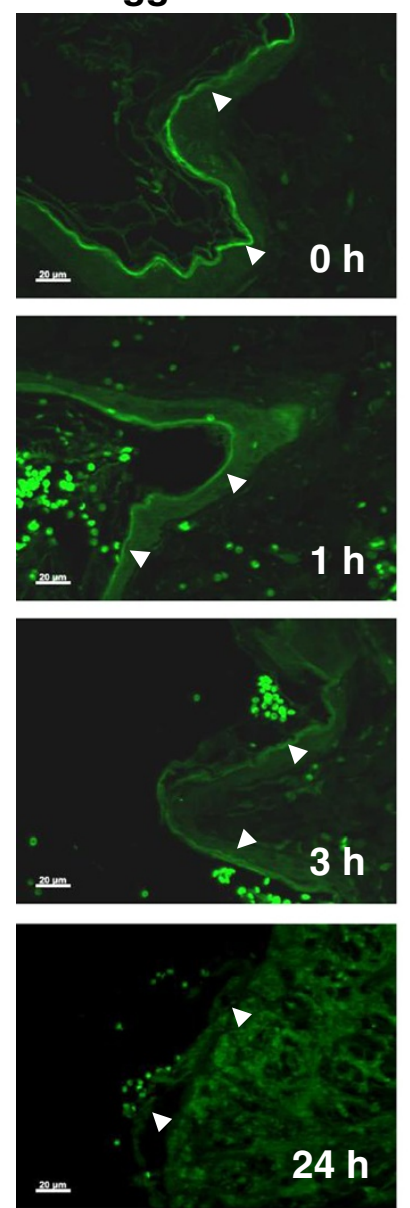

b)

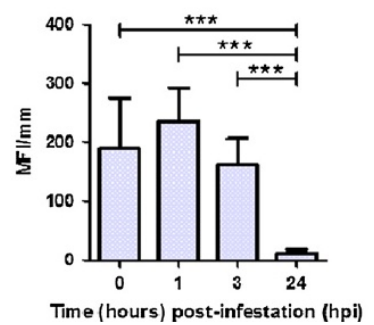

Loricrin
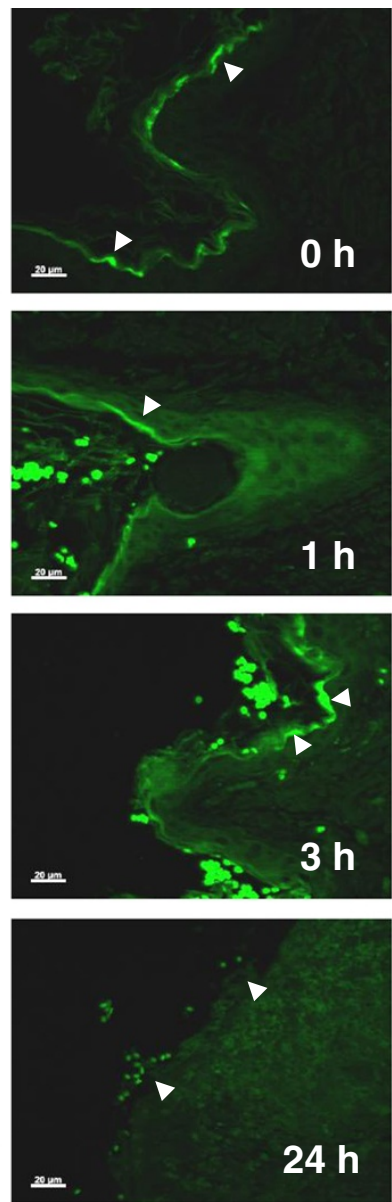

c)

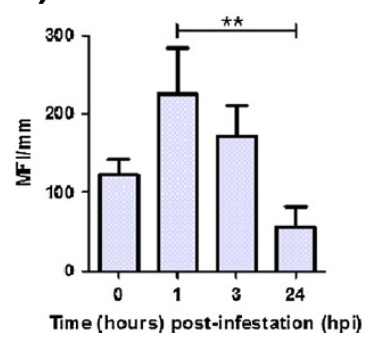

H\&E
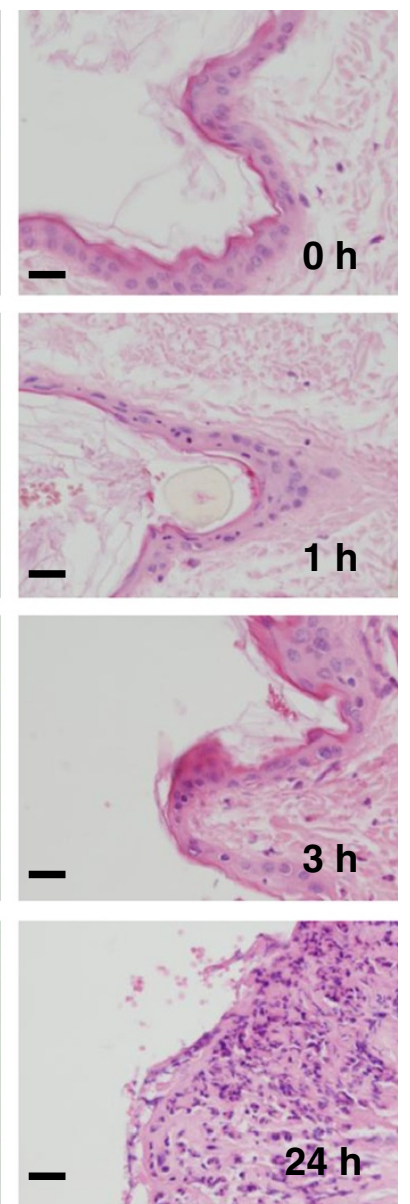

d)

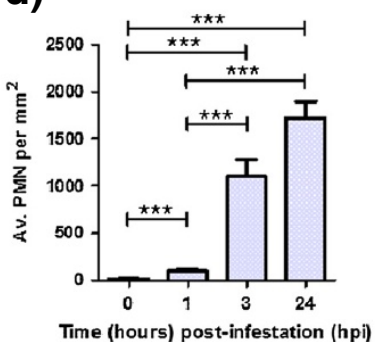

Figure 3 Immunohistochemical labelling of filaggrin and loricrin and changes in skin histopathology following $P$. ovis infestation. (a) Representative images of fluorescence immunohistochemical $(\mathrm{IHC})$ labelling of filaggrin and loricrin and H\&E stained sections from one sheep at time 0, 1, 3 and $24 \mathrm{hpi}$. Scale bars represent $20 \mu \mathrm{m}$. Mean fluorescence intensity (MFI)/mm epithelium for filaggrin (b) and loricrin (c) IHC labelling at time $0,1,3$ and $24 \mathrm{hpi}$. (d) Mean polymorphonuclear cell counts $/ \mathrm{mm}^{2}$ at time 0, 1, 3 and 24 hpi. ${ }^{* *}=p<0.01$, ${ }^{* *}=p<0.001$. Error bars show standard error of the mean (SEM).

Histopathological studies have demonstrated that ticks provoke an influx of inflammatory cells within one to $24 \mathrm{~h}$ of attachment to tick-naïve hosts [41-43]. Although, in contrast to ticks, there is no evidence that the mouthparts of $P$. ovis penetrate the epidermis $[44,45]$ the present study has established that by $1 \mathrm{hpi}, P$. ovis provokes a significant dermal infiltrate of polymorphonuclear cells dominated by eosinophils and after three hours intra-epidermal pustule formation was detectable along with a loss of epidermal architecture and damage to the basement membrane. These observations are consistent with an earlier report of $P$. ovis causing a significant dermal infiltrate, comprising 
Table 1 Immunohistochemical labelling (filaggrin, loricrin), histopathology and transepidermal water loss

\begin{tabular}{|c|c|c|c|c|c|}
\hline Time & $\mathrm{Oh}$ & $1 \mathrm{hpi}$ & $3 \mathrm{hpi}$ & $6 \mathrm{hpi}$ & $24 \mathrm{hpi}$ \\
\hline Filaggrin (average MFI/mm) & $189(34.43-751.01)^{*}$ & $236.16(93.57-469.30)^{*}$ & $160.95(23.69-370.62)^{*}$ & N/A & $11.49(0-44.59)^{*}$ \\
\hline Loricrin (average $\mathrm{MFI} / \mathrm{mm}$ ) & $122.06(83.79-227.59)^{*}$ & $225.15(69.60-402.44)^{*}$ & $171.71(0.09-305.21)^{*}$ & N/A & $55.28(0-213.95)^{*}$ \\
\hline $\begin{array}{l}\text { Mean PMN cell count } \\
\text { per } \mathrm{mm}^{2}\end{array}$ & $9.13(0.97-31.91)^{*}$ & $92.09(12.57-207.93)^{*}$ & $1099.83(410.06-1959.38)^{*}$ & N/A & $1174.16(1098.65-2330.75)$ \\
\hline TEWL $\left(g / m^{2} h\right)$ & $20.54(13.62-29.48)^{*}$ & $598.67(598-662)^{*}$ & $585.17(597.67-637)^{*}$ & $516.46(403.83-597.33)^{*}$ & $396.75(331.17-481)^{*}$ \\
\hline
\end{tabular}

Mean fluorescence intensity (MFI)/mm epithelium for filaggrin and loricrin and mean polymorphonuclear (PMN) cell counts /mm2 at time 0, 1, 3 and 24 hours post-infestation (hpi). Transepidermal water loss (TEWL) $\mathrm{g} /$ $\mathrm{m}^{2} \mathrm{~h}$ at $0,1,3,6$ and $24 \mathrm{hpi}$. *Reference range. 
Table 2 Epidermal changes and their severity at $\mathbf{3}$ and 24 hpi

\begin{tabular}{lllcl}
\hline Time & \multicolumn{1}{c}{ Epidermal pathology } & \multicolumn{3}{c}{ Severity } \\
\cline { 3 - 5 } & & Mild & Moderate & Severe \\
\hline $3 \mathrm{hpi}$ & Pustule formation & 1 case & 2 cases & 0 cases \\
\cline { 2 - 5 } & Loss of architecture & 6 cases & 1 case & 0 cases \\
\cline { 2 - 5 } & Loss of basement membrane & 1 case & 1 case & 7 cases \\
\hline 24 hpi & Pustule formation & 0 cases & 2 cases & 7 cases \\
\cline { 2 - 5 } & Loss of architecture & 1 case & 1 case & 7 cases \\
\cline { 2 - 5 } & Loss of basement membrane & 1 case & 3 cases & 3 cases \\
\hline
\end{tabular}

Results of epidermal changes of 9 sheep at 3 and 24 hours post-infestation (hpi) with P. ovis. The severity of epidermal changes was classified as mild $(<1 / 3$ of the epidermis affected), moderate (1/3-2/3 of the epidermis affected) and severe $(>2 / 3$ of the epidermis affected).

principally eosinophils, accompanied by and neutrophils, $24 \mathrm{~h}$ after infestation of naïve sheep [46]. Although a consistent feature 4 days post infestation with $P$. ovis [46], epidermal hyperplasia was not observed in the present study probably due to the very early nature (1-24 hpi) of the lesions examined [47]. In calves the histological responses to $P$. ovis infestation, although similar to those described in sheep, appear to develop more slowly with only minimal histological changes reported 7 days after the application of two doses of mites at an interval of 21 days [48].

The rapid infiltration of polymorphonuclear cells, observed in the present investigation, is consistent with the presence of potent chemoattractants in P. ovis products. The HDM, D. pteronyssinus, like $P$. ovis, is a

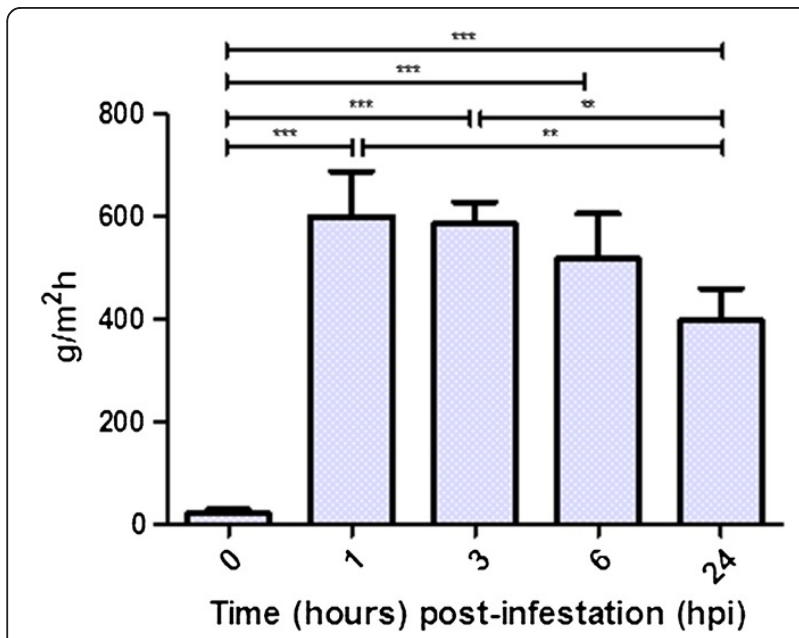

Figure 4 Trans-epidermal water loss (TEWL) following infestation of sheep skin with $P$. ovis. TEWL expressed as grams per square meter per hour, values represent the mean values across four sheep, over two independent sites with triplicate measurements from each site at each time point. ${ }^{* *}=p<0.005$, ${ }^{* *}=p<0.01$. Error bars show standard deviation of values across all samples $(n=4)$. member of the Order Astigmata and in vitro studies have demonstrated the eosinophilic and neutrophilic properties of enzymes, notably $\operatorname{Der} p 1,3$ and 9, produced by these mites and the ability of a HDM extract to induce expression of interleukin-8 (IL8) and tumour necrosis factor alpha (TNF), both of which are potent neutrophil chemoattractants produced by epithelial cells [49-51]. In vitro studies have reported the rapid induction of ovine keratinocyte $I L 8$ expression by $P$. ovis mite washes and whole mite extract and the eosinophil chemoattractant properties of $P$. ovis whole mite extract, and $P$. ovis homologues of HDM chemoattractants, such as, Pso o 1, 3 and 9 have been identified [18,52,53]. These mite products are deposited on the epidermis, probably in the form of faecal pellets, and by analogy with HDM products are likely responsible for the rapid and pronounced infiltration of polymorphonuclear cells documented in the present study. The other aspects of epidermal pathology observed may be caused by the considerable array of enzymes and biologically active compounds present in mite products and also during the host inflammatory response to infestation [54].

The present study also documented the rapid effect of $P$. ovis infestation on epidermal barrier function with a significant increase in TEWL by 1 hpi. The maximal mean TEWL $\left(598.67 \mathrm{~g} / \mathrm{m}^{2} \mathrm{~h}\right)$ was recorded by $1 \mathrm{hpi}$ and then declined, but at $24 \mathrm{hpi}$ the mean value $\left(396.75 \mathrm{~g} / \mathrm{m}^{2} \mathrm{~h}\right)$ was still significantly higher than the baseline value $\left(20.54 \mathrm{~g} / \mathrm{m}^{2} \mathrm{~h}\right)$. The gradual decline of TEWL observed after 1 hpi may be caused by skin crust formation, which is an early characteristic of sheep scab pathology $[3,40]$ thus limiting further transepidermal water loss. In man, TEWL is used as an indicator of impaired epidermal barrier function, however, reliability of TEWL as a marker for epidermal barrier function in other species, such as dogs, has been questioned [55]. TEWL does not appear to have been studied previously in sheep and the influence of ectoparasite infestation on TEWL has not been reported. Compromised barrier function in atopic dermatitis patients may be attributable to the proteolytic activity of Der $p 1$ and $3[15,16]$. In sheep, the mouthparts of $P$. ovis may also impair barrier function by abrading the stratum corneum [56]. However, it is probable that $P$. ovis homologues of the HDM proteases Der $p 1$ and 3, such as Pso o 1 and 3 , also contribute to the increase in TEWL by disruption of tight junctions. These and other proteases may further compromise barrier function by digestion of proteins such as filaggrin, loricrin and involucrin.

There is increasing evidence to suggest that defective skin barrier function in atopic dermatitis leads to a heightened immune response and increases the risk of allergic sensitisation $[55,57,58]$. The present study provides evidence of significant impairment of skin barrier function during a $P$. ovis infestation. As in the pathogenesis of atopic dermatitis 
it is probable that disruption of the epidermal barrier plays a critical role in the subsequent development of the immediate, late phase and delayed hypersensitivity reactions that characterise $P$. ovis infestation by facilitating increased transepidermal passage of mite products that provoke a Th2 dominated immune response [9].

In conclusion the present study has shown that within the first $24 \mathrm{~h}$ of infestation, $P$. ovis elicits a rapid and profound inflammatory response that is dominated by a polymorphonuclear infiltrate and severe epidermal pathology. This response is accompanied by significant decreases in the expression of a number of EDC genes, namely $F L G, I V L$ and $L O R$, reduced presentation of filaggrin and loricrin protein at the epidermal surface and by a significant increase in TEWL. Many of these features are also documented in human and canine atopic dermatitis and suggest that sheep scab may provide a potential model for the study of certain aspects of the initial sensitisation phases during the pathogenesis of atopic dermatitis.

\section{Abbreviations}

HDM: Huse dust mite; TEWL: Transepidermal water loss; NMF: Natural moisturising factor; NGS: Normal goat serum; EDC: Epidermal differentiation complex; MRI: Moredun Research Institute; Hpi: Hours post-infestation; $\mathrm{MFI} / \mathrm{mm}$ : Mean fluorescence intensity/mm.

\section{Competing interests}

The authors declare that they have no competing interests.

\section{Authors' contributions}

MS performed immunohistochemical and histological analysis and prepared the manuscript. TNM supervised the immunohistochemical analysis and performed statistical analysis, participated in the study design and coordination and contributed to the preparation of the manuscript. DF supervised immunohistochemical and GPCR analysis and contributed to the preparation of the manuscript. EJM designed and performed the GPCR analysis. AJN was involved in the cloning of the EDC gene fragments which were used in the $\mathrm{PPCR}$ analysis. AvdB participated in study design and coordination and contributed to the preparation of the manuscript. STGB performed the in vivo trial, collected skin biopsy samples, extracted RNA, performed the TEWL measurements and microarray data analysis, supervised the $\mathrm{GPCR}$ analysis, participated in study design and coordination and contributed to the preparation of the manuscript. All authors read and approved the final manuscript.

\section{Acknowledgements}

This study was funded by the Department for Environment, Food and Rural Affairs (DEFRA), UK under project OD0555. DF, TM and AJN are supported by Scottish Government core funding. We would also like to thank Moredun Bioservices Division for their continued help and expertise.

\section{Author details}

${ }^{1}$ Moredun Research Institute, Pentlands Science Park, Bush Loan, Edinburgh, Midlothian, Scotland EH26 OPZ, United Kingdom. ${ }^{2}$ The Royal (Dick) School of Veterinary Studies, The University of Edinburgh, Midlothian, Scotland EH25 9RG, United Kingdom. ${ }^{3}$ The Roslin Institute, The University of Edinburgh, Division of Veterinary Clinical Sciences, Hospital for Small Animals, Easter Bush Veterinary Centre, Roslin, Midlothian, Scotland EH25 9RG United Kingdom.

Received: 20 August 2012 Accepted: 11 January 2013 Published: 11 February 2013

\section{References}

1. Kirkwood AC: Effect of Psoroptes ovis on the weight of sheep. Vet ReC 1980, 107:469-470.

2. Kirkwood AC: Some observations on the biology and control of the sheep scab mite Psoroptes ovis (hering) in Britain. Vet Parasitol 1985, 18:269-279.

3. Sargison N, Scott P, Penny C, Pirie R: Effect of an outbreak of sheep scab (Psoroptes ovis infestation) during mid-pregnancy on ewe body condition and lamb birthweight. Vet Rec 1995, 136:287-289.

4. Nieuwhof GJ, Bishop SC: Costs of the major endemic diseases of sheep in Great Britain and the potential benefits of reduction in disease impact. Anim Sci 2005, 81:23-29.

5. Hamilton KA, Nisbet AJ, Lehane MJ, Taylor MA, Billingsley PF: A physiological and biochemical model for digestion in the ectoparasitic mite, Psoroptes ovis (Acari: Psoroptidae). Int J Parasitol 2003, 33:773-785.

6. Thomas WR, Smith W: House-dust-mite allergens. Allergy 1998, 53:821-832.

7. Bates PG: Investigations Into the Epidermiology of Ovine Psoroptic mange (sheep scab) in Great Britain, With Special Reference to the Taxonomy of the Genus Psoroptes. Bangor: University of Wales; 1999. PhD Thesis.

8. van den Broek AH, Huntley JF, MacHell J, Taylor M, Bates P, Groves B, Miller $H R$ : Cutaneous and systemic responses during primary and challenge infestations of sheep with the sheep scab mite, Psoroptes ovis. Parasite Immunol 2000, 22:407-414.

9. van den Broek AHM, Huntley JF, Halliwell REW, Machell J, Taylor M, Miller HRP: Cutaneous hypersensitivity reactions to Psoroptes ovis and Der $\mathrm{p} 1$ in sheep previously infested with P. ovis - the sheep scab mite. Vet Immunol Immunopathol 2003, 91:105-117.

10. Elias $P$, Schmuth $M$ : Abnormal skin barrier in the etiopathogenesis of atopic dermatitis. Curr Allergy Asthma Rep 2009, 9:265-272.

11. Feingold KR: Thematic review series: skin lipids. The role of epidermal lipids in cutaneous permeability barrier homeostasis. J Lipid Res 2007, 48:2531-2546.

12. Suter MM, Schulze K, Bergman W, Welle M, Roosje P, Muller EJ: The keratinocyte in epidermal renewal and defence. Vet Dermatol 2009, 20:515-532.

13. Candi E, Schmidt R, Melino G: The cornified envelope: a model of cell death in the skin. Nat Rev Mol Cell Biol 2005, 6:328-340.

14. Beckham SA, Boyd SE, Reynolds S, Willis C, Johnstone M, Mika A, Simerska P, Wijeyewickrema LC, Smith Al, Kemp DJ, Pike RN, Fischer K: Characterization of a serine protease homologous to house dust mite group 3 allergens from the scabies mite Sarcoptes scabiei. J Biol Chem 2009, 284:34413-34422.

15. Wan H, Winton HL, Soeller C, Tovey ER, Gruenert DC, Thompson PJ, Stewart GA, Taylor GW, Garrod DR, Cannell MB, Robinson C: Der $p 1$ facilitates transepithelial allergen delivery by disruption of tight junctions. J Clin Invest 1999, 104:123-133.

16. Wan H, Winton HL, Soeller C, Taylor GW, Gruenert DC, Thompson PJ, Cannell MB, Stewart GA, Garrod DR, Robinson C: The transmembrane protein occludin of epithelial tight junctions is a functional target for serine peptidases from faecal pellets of Dermatophagoides pteronyssinus. Clin Exp Allergy 2001, 31:279-294.

17. Rawlings AV, Harding CR: Moisturization and skin barrier function. Dermatol Ther 2004, 17(Suppl 1):43-48.

18. Burgess ST, Frew D, Nunn F, Watkins CA, McNeilly TN, Nisbet AJ, Huntley JF: Transcriptomic analysis of the temporal host response to skin infestation with the ectoparasitic mite Psoroptes ovis. BMC Genomics 2010, 11:624.

19. Sugiura H, Ebise H, Tazawa T, Tanaka K, Sugiura Y, Uehara M, Kikuchi K, Kimura T: Large-scale DNA microarray analysis of atopic skin lesions shows overexpression of an epidermal differentiation gene cluster in the alternative pathway and lack of protective gene expression in the cornified envelope. Br J Dermatol 2005, 152:146-149.

20. Kim BE, Leung DYM, Boguniewicz M, Howell MD: Loricrin and involucrin expression is down-regulated by Th2 cytokines through STAT-6. Clin Immunol 2008, 126:332-337.

21. Irvine AD: Fleshing out filaggrin phenotypes. J Invest Dermatol 2007, 127:504-507.

22. Wilson DR, Maibach H: Transepidermal water loss: a review. In Cutaneous Investigations in Health and Disease: Non-invasive Methods and Instrumentation. 1st edition. Edited by Leveque J-L. New York: Dekker; 1989:113-134.

23. Pinnagoda J, Tupker RA, Agner T, Serup J: Guidelines for transepidermal water loss (TEWL) measurement. A report from the Standardization 
Group of the European Society of Contact Dermatitis. Contact Dermatitis 1990, 22:164-178.

24. Seidenari S, Giusti G: Objective assessment of the skin of children affected by atopic dermatitis: a study of $\mathrm{pH}$, capacitance and TEWL in eczematous and clinically uninvolved skin. Acta Derm Venereol 1995, 75:429-433.

25. Werner $\mathrm{Y}$, Lindberg $\mathrm{M}$ : Transepidermal water loss in dry and clinically normal skin in patients with atopic dermatitis. Acta Derm Venereol 1985, 65:102-105.

26. Shimada K, Yoon JS, Yoshihara T, Iwasaki T, Nishifuji K: Increased transepidermal water loss and decreased ceramide content in lesional and non-lesional skin of dogs with atopic dermatitis. Vet Dermatol 2009, 20:541-546.

27. Schroeder A, Mueller O, Stocker S, Salowsky R, Leiber M, Gassmann M, Lightfoot S, Menzel W, Granzow M, Ragg T: The RIN: an RNA integrity number for assigning integrity values to RNA measurements. BMC Mol Biol 2006, 7:3.

28. McNeilly TN, Baker A, Brown JK, Collie D, MacLachlan G, Rhind SM, Harkiss $\mathrm{GD}$ : Role of alveolar macrophages in respiratory transmission of visna/ maedi virus. J Virol 2008, 82:1526-1536.

29. Chang J-S, Russell GC, Jann O, Glass EJ, Werling D, Haig DM: Molecular cloning and characterization of Toll-like receptors 1-10 in sheep. Vet Immunol Immunopathol 2009, 127:94-105.

30. Schmittgen TD, Livak KJ: Analyzing real-time PCR data by the comparative C-T method. Nat Protoc 2008, 3:1101-1108.

31. Livak KJ, Schmittgen TD: Analysis of relative gene expression data using real-time quantitative PCR and the $2(\mathrm{~T})(-$ Delta Delta $\mathrm{C})$ method. Methods 2001, 25:402-408.

32. Abramoff MD, Magalhaes PJ, Ram SJ: Image processing with ImageJ. Biophotonics Int 2004, 11:36-42.

33. Hamid Q, Boguniewicz M, Leung DY: Differential in situ cytokine gene expression in acute versus chronic atopic dermatitis. J Clin Invest 1994, 94:870-876.

34. Homey B, Steinhoff M, Ruzicka T, Leung DYM: Cytokines and chemokines orchestrate atopic skin inflammation. J Allergy Clin Immunol 2006, 118:178-189.

35. Santoro D, Marsella R, Bunick D, Graves TK, Campbell KL, Ahrens K Expression and distribution of canine filaggrin in the skin of healthy and atopic beagles [abstract]. Vet Dermatol 2010, 21:323.

36. Howell MD, Kim BE, Gao P, Grant AV, Boguniewicz M, DeBenedetto A, Schneider L, Beck LA, Barnes KC, Leung DYM: Cytokine modulation of atopic dermatitis filaggrin skin expression. J Allergy Clin Immunol 2007, 120:150-155.

37. Sehra S, Yao Y, Howell MD, Nguyen ET, Kansas GS, Leung DYM, Travers JB, Kaplan MH: IL-4 regulates skin homeostasis and the predisposition toward allergic skin inflammation. J Immunol 2010, 184:3186-3190.

38. Irvine AD, McLean WHI, Leung DYM: Filaggrin mutations associated with skin and allergic diseases. N Engl J Med 2011, 365:1315-1327.

39. Chervet L, Galichet A, McLean WHI, Chen H, Suter MM, Roosje PJ, Müller EJ: Missing C-terminal filaggrin expression, NFkappaB activation and hyperproliferation identify the dog as a putative model to study epidermal dysfunction in atopic dermatitis. Exp Dermatol 2010, 19:e343-e346.

40. Bates PG: The pathogenesis and aging of sheep scab lesions. Part 2: Ageing lesions. State Vet J 1997, 7:13-16.

41. Tatchell RJ, Moorhouse DE: The feeding processes of the cattle tick Boophilus microplus (Canestrini). II. The sequence of host-tissue changes. Parasitology 1968, 58:441-459.

42. Allen JRDB, Kemp DH: Histology of bovine skin reactions to Ixodes holocyclus Neumann. Can J Comp Med 1977, 41:26-35.

43. Brown SJ, Bagnall BG, Askenase PW: Ixodes holocyclus: kinetics of cutaneous basophil responses in naive, and actively and passively sensitized guinea pigs. Exp Parasitol 1984, 57:40-47.

44. Sinclair AN, Kirkwood AC: Feeding behaviour of Psoroptes ovis. Vet Rec $1983,112: 65$

45. Sinclair AN, Filan SJ: Lipid ingestion from sheep epidermis by Psoroptes ovis (Acari: Psoroptidae). Vet Parasitol 1989, 31:149-164.

46. van den Broek AHM, Else RW, Huntley JF, Machell J, Taylor MA, Miller HRP: Early innate and longer-term adaptive cutaneous immunoinflammatory responses during primary infestation with the sheep scab mite, Psoroptes ovis. J Comp Pathol 2004, 131:318-329.
47. Videmont E, Mariani C, Vidal S, Pin D: Characterization of the canine skin barrier restoration following acute disruption by tape stripping. Vet Dermatol 2012, 23:103-110.

48. Stromberg PC, Fisher WF: Dermatopathology and immunity in experimental Psoroptes ovis (Acari:Psoroptidae) infestation of naive and previously exposed Hereford cattle. Am J Vet Res 1986, 47:1551-1560.

49. Lau LCK, Leir SH, Lackie P, Shute JK, Howarth PH: House dust mite allergen cleaves epithelial adhesion molecules and activates epithelial cells by an IgE independent pathway. Am J Respir Crit Care Med 1999, 159:A179.

50. Fahy O, Hammad H, Sénéchal S, Pestel J, Tonnel AB, Wallaert B, Tsicopoulos $A$ : Synergistic effect of diesel organic extracts and allergen Der $p 1$ on the release of chemokines by peripheral blood mononuclear cells from allergic subjects. Am J Respir Cell Mol Biol 2000, 23:247-254.

51. Sun G, Stacey MA, Schmidt M, Mori L, Mattoli S: Interaction of mite allergens Der p3 and Der p9 with protease-activated receptor-2 expressed by lung epithelial cells. J Immunol 2001, 167:1014-1021.

52. Wildblood LA, Jones DG: Stimulation of the in vitro migration of ovine eosinophils by factors derived from the sheep scab mite, Psoroptes ovis. Vet Res Commun 2007, 31:197-206.

53. Watkins CA, Mackellar A, Frew D, Mackie C, George A, Hopkins J, Burgess STG, MCNeilly TN, Huntley JF: Gene expression profiling of ovine keratinocytes stimulated with Psoroptes ovis mite antigen - a preliminary study. Parasite Immunol 2009, 31:304-311.

54. Nisbet AJ, Billingsley PF: Immunological control of scab mites: digestive enzymes as candidate compounds. Vet Parasitol 1999, 83:231-239.

55. Olivry T: Is the skin barrier abnormal in dogs with atopic dermatitis? Vet Immunol Immunopathol 2011, 144:11-16.

56. Blake BH, Bay DE, Meola SM, Price MA: Morphology of the mouthparts of the sheep scab mite, Psoroptes ovis. Ann Entomol Soc Am 1978, 71:289-294.

57. Marsella R, Samuelson D: Unravelling the skin barrier: a new paradigm for atopic dermatitis and house dust mites. Vet Dermatol 2009, 20:533-540.

58. Elias PM, Steinhoff M: "outside-to-inside" (and now back to "outside") pathogenic mechanisms in atopic dermatitis. J Invest Dermatol 2008, 128:1067-1070.

doi:10.1186/1297-9716-44-11

Cite this article as: Stoeckli et al:: The effect of Psoroptes ovis infestation on ovine epidermal barrier function. Veterinary Research 2013 44:11.

\section{Submit your next manuscript to BioMed Central and take full advantage of:}

- Convenient online submission

- Thorough peer review

- No space constraints or color figure charges

- Immediate publication on acceptance

- Inclusion in PubMed, CAS, Scopus and Google Scholar

- Research which is freely available for redistribution 